\title{
Front Matter: Volume 7517
}

, "Front Matter: Volume 7517," Proc. SPIE 7517, Photonics and Optoelectronics Meetings (POEM) 2009: Optical Storage and New Storage Technologies, 751701 (4 November 2009); doi: 10.1117/12.853185

SPIE. Event: Photonics and Optoelectronics Meetings 2009, 2009, Wuhan, China 


\title{
PROCEEDINGS OF SPIE
}

Photonics and Optoelectronics Meetings (POEM) 2009

\section{Optical Storage and \\ New Storage Technologies}

\author{
Masud Mansuripur \\ Changsheng Xie \\ Xiangshui Miao \\ Editors
}

\section{8-10 August 2009 \\ Wuhan, China}

Organized by

Wuhan National Laboratory for Optoelectronics (China)

Sponsored by

Chinese Optical Society • Huazhong University of Science and Technology (China) • China Hubei Provincial Science Technology Department • Administration Committee of Wuhan East Lake High-Tech Development Zone (China) • The State Optoelectronic Information Industry Base of China

\section{Supported by}

Ministry of Education of China - Optical Society of America - Laser Institute of America • Frontiers of Optoelectronics in China • Editorial Office of Optics \& Optoelectronics Technology • Opticsjournal.net OFweek.com • The China Science-Meeting Online • Laser Manufacture News

Published by

SPIE 
The papers included in this volume were part of the technical conference cited on the cover and title page. Papers were selected and subject to review by the editors and conference program committee. Some conference presentations may not be available for publication. The papers published in these proceedings reflect the work and thoughts of the authors and are published herein as submitted. The publisher is not responsible for the validity of the information or for any outcomes resulting from reliance thereon.

Please use the following format to cite material from this book:

Author(s), "Title of Paper," in Photonics and Optoelectronics Meetings (POEM) 2009: Optical Storage and New Storage Technologies, edited by Masud Mansuripur, Changsheng Xie, Xiangshui Miao, Proceedings of SPIE Vol. 7517 (SPIE, Bellingham, WA, 2009) Article CID Number.

ISSN 0277-786X

ISBN 9780819479068

Published by

SPIE

P.O. Box 10, Bellingham, Washington 98227-0010 USA

Telephone +1 3606763290 (Pacific Time) · Fax +1 3606471445

SPIE.org

Copyright (C) 2009, Society of Photo-Optical Instrumentation Engineers

Copying of material in this book for internal or personal use, or for the internal or personal use of specific clients, beyond the fair use provisions granted by the U.S. Copyright Law is authorized by SPIE subject to payment of copying fees. The Transactional Reporting Service base fee for this volume is $\$ 18.00$ per article (or portion thereof), which should be paid directly to the Copyright Clearance Center (CCC), 222 Rosewood Drive, Danvers, MA 01923. Payment may also be made electronically through CCC Online at copyright.com. Other copying for republication, resale, advertising or promotion, or any form of systematic or multiple reproduction of any material in this book is prohibited except with permission in writing from the publisher. The CCC fee code is 0277-786X/09/\$18.00.

Printed in the United States of America.

Publication of record for individual papers is online in the SPIE Digital Library.

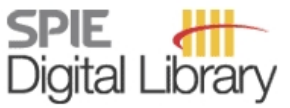

SPIEDigitalLibrary.org

Paper Numbering: Proceedings of SPIE follow an e-First publication model, with papers published first online and then in print and on CD-ROM. Papers are published as they are submitted and meet publication criteria. A unique, consistent, permanent citation identifier (CID) number is assigned to each article at the time of the first publication. Utilization of CIDs allows articles to be fully citable as soon they are published online, and connects the same identifier to all online, print, and electronic versions of the publication. SPIE uses a six-digit CID article numbering system in which:

- The first four digits correspond to the SPIE volume number.

- The last two digits indicate publication order within the volume using a Base 36 numbering system employing both numerals and letters. These two-number sets start with 00, 01, 02, 03, 04, $05,06,07,08,09,0 A, 0 B \ldots 0 Z$, followed by 10-1Z, 20-2Z, etc.

The CID number appears on each page of the manuscript. The complete citation is used on the first page, and an abbreviated version on subsequent pages. Numbers in the index correspond to the last two digits of the six-digit CID number. 


\section{Contents}

vii Symposium Committees

xi Conference Committee

PHOTONICS AND OPTOELECTRONICS MEETINGS (POEM) 2009: OPTICAL STORAGE AND NEW STORAGE TECHNOLOGIES

751702 A fast video watermarking scheme for embedded device identity verification [7517-35] J. Liu, Wuhan Institute of Technology (China) and Huazhong Univ. Of Science and Technology (China); F. Hu, Hubei Univ. of Technology (China); J. Wang, Huazhong Univ. of Science and Technology (China)

751703 A hybrid data compression approach for online backup service [7517-29] H. Wang, K. Zhou, M. Qin, Huazhong Univ. of Science and Technology (China)

751704 A new photochromic diarylethene for polarization optical recording based on thiazole and a six-membered aryl unit [7517-23]

H. Li, S. Pu, G. Liu, W. Liu, Jiangxi Science and Technology Normal Univ. (China)

751705 Concentric piecewise vector beam for superresolution and high focal depth [7517-04] X. Gao, Hangzhou Dianzi Univ. (China) and Univ. of Shanghai for Science and Technology (China); X. Wang, Focused Photonics (Hangzhou) Inc. (China); J. Li, China Jiliang Univ. (China); S. Hu, Hangzhou Dianzi Univ. (China); S. Zhuang, Univ. of Shanghai for Science and Technology (China)

751706 Effects of $\mathrm{O}_{2}$ /Ar ratio and UV illumination on the properties of radio frequency sputtered TeOx thin films [7517-44]

X. Wang, Y. Geng, D. Gu, Shanghai Institute of Optics and Fine Mechanics (China)

751707 Efficient synthesis, photochromism, and holographic optical recording of a photochromic diarylethene bearing a pyrrole unit [7517-17]

G. Liu, S. Pu, C. Fan, Jiangxi Science and Technology Normal Univ. (China)

751708 Efficient wear-leveling algorithm for Nand flash memory based solid-state disk [7517-20]

G. Zhou, J. Chen, T. Li, H. Hu, Huazhong Univ. of Science and Technology (China)

751709 Fabrication of biochip based on CD/DVD manufacturing technology [7517-08]

P. Li, B. Xu, L. Li, M. Yan, L. Pan, Tsinghua Univ. (China)

7517 OA Focal properties of cylindrically polarized beams by a high numerical aperture parabolic mirror [7517-38]

L. Guo, South China Normal Univ. (China) and GuangDong Polytechnic Normal Univ. (China); Z. Tang, C. Liang, Z. Tan, South China Normal Univ. (China); J. Liu, GuangDong Polytechnic Normal Univ. (China) 
7517 OB Holographic properties of $\mathrm{SiO}_{2}$-nanoparticle dispersed PVA/AA photopolymer [7517-51] Y. Wang, S. Wang, R. Li, M. Huang, Henan Univ. (China)

7517 OC Kinetic, electrochemical, and optical storage of a novel diarylethene [7517-26] W. Liu, S. Pu, C. Fan, G. Liu, S. Cui, Jiangxi Science and Technology Normal Univ. (China)

7517 OD Measurement mark profiles of digital versatile disc and multilevel read-only disc with atomic force microscopy [7517-21]

H. Liu, Tsinghua Univ. (China) and Yanshan Univ. (China); J. Pei, Y. Ni, L. Pan, Tsinghua Univ. (China)

7517 OE Nanobiomedicine crystal-inspired optical quantum bit storage [7517-09]

Y. Fang, F. Wang, M. Rong, Fudan Univ. (China)

7517 OF Nonvolatile hologram storage properties in In:Fe:Cu:LiNbO 3 crystals (Invited Paper) [7517-07]

B. Yu, S. Luo, H. Liu, H. Lin, X. Sun, Harbin Institute of Technology (China)

7517 OG Novel constant linear velocity control method for the multilevel run-length limited read-only disc [7517-10]

M. Yan, J. Pei, L. Pan, H. Wang, Tsinghua Univ. (China)

$7517 \mathrm{OH} \quad$ Optical and thermal properties of nickel(II) hydrazone complex for recordable blu-ray storage [7517-15]

Z. Chen, Y. Wu, Heilongjiang Univ. (China) and Shanghai Institute of Optics and Fine Mechanics (China); D. GU, F. Gan, Shanghai Institute of Optics and Fine Mechanics (China)

7517 Ol Photochromic property and application for optical recording of a new diarylethene [7517-24]

P. Yan, S. Pu, A. Chen, G. Liu, W. Liu, Jiangxi Science and Technology Normal Univ. (China)

7517 0J Photoinduced anisotropy in a new diarylethene bearing a six-membered aryl [7517-19] A. Chen, Jiangxi Science and Technology Normal Univ. (China) and East China Institute of Technology (China); S. Pu, P. Yan, Jiangxi Science and Technology Normal Univ. (China); Z. Le, East China Institute of Technology (China); W. Liu, Jiangxi Science and Technology Normal Univ. (China)

7517 OK Photorefractive properties of doubly doped lithium niobate crystals with $\mathrm{Zr}$ and Fe [7517-06] H. Lin, B. Yu, C. Xu, S. Luo, H. Liu, H. Shi, X. Sun, Harbin Institute of Technology (China)

7517 OM Recording performance evaluation of high-density patterned media [7517-18]

S. Xu, J. Chen, G. Zhou, Huazhong Univ. of Science and Technology (China)

7517 ON Research on application of superresolving technology regarding Gaussian beam in high-density optical data storage (Invited Paper) [7517-27]

S. Wang, Tianjin Polytechnic Univ. (China); H. Ruan, National Engineering Research Ctr. for Optical Disks and Application (China)

751700 Reversible molecule switching properties of an assymmetrical photochromic diarylethene bearing an ethoxy group [7517-16]

C. Fan, S. Pu, G. Liu, W. Liu, Jiangxi Science and Technology Normal Univ. (China) 
7517 OP Simulation and experiment on probe inducing surface plasmon resonance nanolithography system [7517-12]

C. Zhao, W. Xu, X. Hong, X. Li, Y. Wang, Shanghai Institute of Optics and Fine Mechanics (China)

$75170 Q \quad$ Synthesis and application for high density optical storage of a new photochromic diarylethene [7517-22]

S. Cui, S. Pu, G. Liu, W. Liu, Jiangxi Science and Technology Normal Univ. (China)

7517 OR Synthesis, kinetics, and electrochemical properties of a new photochromic diarylethene [7517-25]

W. Miao, S. Pu, W. Liu, G. Liu, Jiangxi Science and Technology Normal Univ. (China)

7517 OS Transient phase change in picosecond laser pulse-driven crystallization process of as-deposited amorphous thin films (Invited Paper) [7517-50]

Y. Wang, Shanghai Institute of Optics and Fine Mechanics (China); F. Y. Zuo, Sun Yat-Sen Univ. (China); H. Huang, F. X. Zhai, Shanghai Institute of Optics and Fine Mechanics (China); T. S. Lai, Sun Yat-Sen Univ. (China); Y. Q. Wu, Shanghai Institute of Optics and Fine Mechanics (China)

7517 OT Highly reliable data layout schemes for very large scale storage systems [7517-45]

D. Luo, H. Zhong, W. Wu, Huazhong Univ. of Science and Technology (China)

7517 OU A method of improving the performance of continuous data protection system (Invited Paper) [7517-01]

D. Huo, Q. Cao, C. Xie, J. Yang, Huazhong Univ. of Science and Technology (China)

7517 OV A new cryptographic read/write flow for networked storage system [7517-33]

C. Pei, C. Xie, J. Huang, Huazhong Univ. of Science and Technology (China)

7517 OW Concurrent processes of CDP in object-based file system [7517-14]

J. Yao, Q. Cao, J. Huang, Huazhong Univ. of Science and Technology (China)

7517 OX Enhancing traffic performance in hierarchical DHT system by exploiting network proximity [7517-53]

H. Zhong, W. Wu, C. Pei, C. Zhang, Huazhong Univ. of Science and Technology (China)

7517 OY Fabrication and properties of $\mathrm{Nd}(\mathrm{Tb}, \mathrm{Dy}) \mathrm{Co} / \mathrm{Cr}$ films with perpendicular magnetic anisotropy [7517-46]

W. Cheng, X. Miao, J. Yan, X. Cheng, Huazhong Univ. of Science and Technology (China)

$7517 \mathrm{OZ}$ Mathematical analysis of temperature distribution in hybrid recording film using AFM tip writing [7517-52]

J. B. Yan, Wuhan National Lab. for Optoelectronics (China) and Shandong SinoChip Semiconductors Ltd. (China); Z. Y. Li, K. F. Dong, Huazhong Univ. of Science and Technology (China); W. M. Cheng, Wuhan National Lab. for Optoelectronics (China) and Huazhong Univ. of Science and Technology (China); G. Q. Lin, Huazhong Univ. of Science and Technology (China); X. S. Miao, Wuhan National Lab. for Optoelectronics (China) and Huazhong Univ. of Science and Technology (China) 
751710 Metadata management for CDP in object-based file system [7517-13]

J. Yao, Q. Cao, J. Huang, Huazhong Univ. of Science and Technology (China)

751711 Performance analysis of data deduplication technology for storage [7517-55] J. Wang, H. Huang, Huazhong Univ. of Science and Technology (China); J. Fu, Hubei Provincial Meteorological Service Ctr. Administrator (China); P. Wang, J. Liu, Y. Yang, Huazhong Univ. of Science and Technology (China)

751712 Performance comparison of FCoE and iSCSI [7517-40]

W. Tong, Huazhong Univ. of Science and Technology (China)

751713 QoS optimization in object storage system [7517-05]

L. Xiao, C. Wu, Q. Wei, Huazhong Univ. of Science and Technology (China) and Wuhan National Lab. for Optoelectronics (China)

751714 Research of storage encryption based on multi-protocol RAID [7517-32]

C. Pei, C. Xie, L. Zhang, Huazhong Univ. of Science and Technology (China)

751715 Research on load optimization of DHT-based hierarchy peer-to-peer system [7517-36] H. Zhong, D. Luo, W. Wu, L. Xiao, Huazhong Univ. of Science and Technology (China)

751716 Simulation of giant magnetoimpedance in single layer and sandwiched thin films [7517-48] F. Jin, W. Mo, China Univ. of Geosciences (China); H. Sun, W. Cheng, Huazhong Univ. of Science and Technology (China)

Author Index 


\title{
Symposium Committees
}

\author{
General Conference Chairs \\ Chaohui Ye, Chinese Academy of Sciences (China) and Wuhan \\ National Laboratory for Optoelectronics (China) \\ Ahmed H. Zewail, 1999 Nobel Prize Winner in Chemistry; Physical \\ Biology Center for Ultrafast Science and Technology, California \\ Institute of Technology (United States) \\ Bingkun Zhou, Chinese Academy of Sciences (China) and Tsinghua \\ University (China)
}

International Advisory Committee

Peigen Li, Chair, Huazhong University of Science and Technology

(China)

Victor V. Apollonov, General Physics Institute (Russian Federation)

Hegao Cai, Harbin Institute of Technology (China)

Britton Chance, Pennsylvania University (United States)

Ruiliang Chen, Université Laval (Canada)

Yong Chen, Ecole Normale Superieure (France)

Yi-Bing Cheng, Monash University (Australia)

Connie Chang-Hasnain, University of California, Berkeley

(United States)

Russell D. Dupuis, Georgia Institute of Technology (United States)

Don Giddens, Georgia Institute of Technology (United States)

Michael Grätzel, Ecole Polyłechnique Fédérale de Lausanne

(Switzerland)

Dianyuan Fan, Shanghai Institute of Optics and Fine Mechanics

(China)

Xun Hou, Xi'an Institute of Optics and Precision Mechanics (China)

Desheng Jiang, Wuhan University of Technology (China)

Tingye Li, AT\&T Labs (retired) (United States)

Songhao Liu, South China Normal University (China)

Jurgen Michel, Massachusetts Institute of Technology (United States)

David A.B. Miller, Stanford University (United States)

Liwei Lin, University of California, Berkeley (United States)

Bo Liu, National Data Storage Institute (Singapore) 
Mike O'Mahony, University of Essex (United Kingdom)

Hanben Niu, Shenzhen University (China)

Zihe Rao, Nankai University (China)

Xubang Shen, Chinese Academy of Sciences (China)

Kang L. Wang, University of California, Los Angeles (United States)

Naiyan Wang, Institute of Atomic Energy (China)

Lihong Wang, Washington University in St. Lovis (United States)

Qiming Wang, Institute of Semiconductors, Chinese Academy of Sciences (China)

Ian H. White, University of Cambridge (United Kingdom)

Bernd Wilhelmi, Friedric-Schiller-Universität Jena (Germany)

C. P. Wong, Georgia Institute of Technology (United States)

Ke Wu, Université de Montréal (Canada)

Zhizhan Xu, Shanghai Institute of Optics and Fine Mechanics (China)

X. C. Zhang, Rensselaer Polytechnic Institute (United States)

Zisen Zhao, Fiberhome (China) and Wuhan Research Institute (China)

Bingkun Zhou, Tsinghua University (China)

Jimmy Zhu, Carnegie Mellon University (United States)

Zhongliang Zhu, Chinese Academy of Sciences (China)

Program Committee

Qingming Luo, Chair, Wuhan National Laboratory for Optoelectronics (China)

Hiroshi Amano, Meijo University (Japan)

Chin Hsin Chen, National Chiao Tung University (Taiwan, China)

Yong Chen, École Normale Supérieure Paris, CNRS (France)

Dianyuan Fan, Shanghai Institute of Optics and Fine Mechanics (China)

Fuxi Gan, Shanghai Institute of Optics and Fine Mechanics, Chinese

Academy of Sciences (China)

Michael Grätzel, Ecole Polyłechnique Fédérale de Lausanne

(Switzerland)

Dieter Stefan Jäger, Universität Duisburg-Essen (Germany)

Shuisheng Jian, Chinese Academy of Sciences (China)

Desheng Jiang, Chinese Academy of Engineering (China)

Masud Mansuripur, College of Optical Sciences, The University of

Arizona (United States)

Valery V. Tuchin, Saratov State University (Russian Federation)

Lihong Wang, Washington University in St. Louis (United States)

Horst Weber, Technische Universität Berlin (Germany) 
Hequan Wu, Chinese Academy of Engineering (China)

Changsheng Xie, Wuhan National Laboratory for Optoelectronics (China)

Jianquan Yao, Tianjing University (China) and Wuhan National Laboratory for Optoelectronics (China)

Zisen Zhao, Fiberhome (China) and Wuhan Research Institute (China)

Local Organizing Committee

Lin Lin, Chair, Wuhan National Laboratory for Optoelectronics (China)

Yaming Xia, Chair, Administration Committee of Wuhan East Lake Hi-tech Development Zone (China)

Changqing Chen, Wuhan National Laboratory for Optoelectronics (China)

Huafen Chen, Administration Committee of Wuhan East Lake Hi-tech Development Zone (China)

Ling Fu, Wuhan National Laboratory for Optoelectronics (China)

Dongsheng Jiang, State Key Laboratory of Solid State Lasers (China)

Pengcheng Li, Wuhan National Laboratory for Optoelectronics (China)

Deming Liu, Wuhan National Laboratory for Optoelectronics (China)

Xiangshui Miao, Wuhan National Laboratory for Optoelectronics (China)

Junqiang Sun, Wuhan National Laboratory for Optoelectronics (China)

Qianwen Sun, Administration Committee of Wuhan East Lake Hi-tech Development Zone (China)

Peng Wang, Changchun Institute of Applied Chemistry, Chinese Academy of Sciences (China)

Jinzhong Yu, Institute of Semiconductors, Chinese Academy of Sciences (China)

Xiao Zhu, Wuhan National Laboratory for Optoelectronics (China) 
Downloaded From: https://www.spiedigitallibrary.org/conference-proceedings-of-spie on 25 Apr 2023

Terms of Use: https://www.spiedigitallibrary.org/terms-of-use 


\title{
Conference Committee
}

\author{
Conference Chairs \\ Masud Mansuripur, College of Optical Sciences, The University of \\ Arizona (United States) \\ Changsheng Xie, Wuhan National Laboratory for Optoelectronics \\ (China) \\ Xiangshui Miao, Wuhan National Laboratory for Optoelectronics \\ (China)
}

Program Committee

Jun Ding, National University of Singapore (Singapore)

Dan Feng, Wuhan National Laboratory for Optoelectronics (China)

Xiufeng Han, Institute of Physics, Chinese Academy of Sciences (China)

Lisong Hou, Shanghai Institute of Optics and Fine Mechanics, Chinese Academy of Sciences (China)

Qingyuan Jin, Fudan University (China)

Takashi Kikukawa, TDK (Japan)

Yinyin Lin, Fudan University (China)

Bo Liu, Data Storage Institute (Singapore)

Masud Mansuripur, College of Optical Sciences, The University of Arizona (United States)

Xiangshui Miao, Wuhan National Laboratory for Optoelectronics (China)

Longfa Pan, Optical Memory National Engineering Research Center, Tsinghua University (China)

No-Cheol Park, Yonsei University (Korea)

Hao Ruan, National Engineering Research Center of Optical Disk and Application (China)

Luping Shi, Data Storage Institute (Singapore)

Xiudong Sun, Harbin Institute of Technology (China)

Din Ping Tsai, National Taiwan University, (Taiwan, China)

Matthias Wuttig, RWTH-Aachen University (Germany)

Changsheng Xie, Wuhan National Laboratory for Optoelectronics (China)

Jimmy Zhu, Carnegie Mellon University (United States)

Local Organizing Committee Chair

Xiangshui Miao, Wuhan National Laboratory for Optoelectronics (China) 
Downloaded From: https://www.spiedigitallibrary.org/conference-proceedings-of-spie on 25 Apr 2023

Terms of Use: https://www.spiedigitallibrary.org/terms-of-use 